\title{
AS ESQUERDAS E ISRAEL: MUITA MILITÂNCIA E POUCO DIÁLOGO
}

Ariel Finguerut ${ }^{1}$

"History, it has been well Said, yields her secrets only to those Who Begin with the present" Robert Nisbet

Quando nos perguntamos o que é ser de "esquerda" ou em outros termos, ser progressista ou liberal ou mesmo socialista é sempre uma tarefa difícil pois o contexto histórico é decisivo assim como a cultura política do país e do momento analisado. Ser de esquerda nos EUA de hoje pode ser sinônimo de ser de direita em outros lugares. A esquerda no Brasil assim como parte da esquerda europeia pode ser bem caracteriza entre o antes e o depois de chegar ao poder. Outro problema típico desse exercício é encontrar posturas, ideias e estratégias que apontam para semelhanças mais fortes do que diferenças "direita" e a "esquerda".

O que buscaremos brevemente discutir aqui é o comportamento da esquerda - e da opinião pública internacional por ela influenciada - que hoje critica Israel mas que já foi no passado defensora ou no limite simpática ao projeto sionista. 0 sionismo tornouse para parte da esquerda um projeto sinônimo de imperialismo, mas não é preciso grandes digressões para lembrar que o sionismo como projeto já foi também sinônimo de um sonho socialista. E o contrário também é verdade, os conservadores que hoje defendem Israel e seu militarismo e expansão territorial, não há muito tempo, duvidava da viabilidade de uma democracia plena no Oriente Médio. Por que, uma parte considerável da esquerda - latino-americana, brasileira, mas também vale, entre

\footnotetext{
${ }^{1}$ Doutor em Ciência Política. Professor do Centro Universitário Senac. Membro da Comissão editorial do Boletim Eletrônico Malala.
} 
socialistas europeus e progressistas nos EUA - mudou de percepção quanto a Israel? Não é difícil encontrarmos professores, jornalistas, intelectuais de esquerda a considerar Israel (assim como os EUA) como uma nação terrorista. Como se o David do passado fosse agora o Golias.

Joshua Muravchik (2014) em livro recém lançado apresenta alguns apontamentos interessantes para explicar essa transformação. A começar que o autor levanta uma série de fatos concretos sobre Israel, que seriam bons motivos para deixar qualquer liberal ou social-democrata entusiasmado. Israel tem plena liberdade de expressão ${ }^{2}$ e liberdade religiosa, é um estado historicamente formado por imigrantes e refugiados e tem uma vibrante economia digital com startups e empresas de alta tecnologia. Israel tem mais prêmios Nobel que a França, por exemplo. Para os progressistas basta lembrar que as forças armadas, sem alarde, aceitam gays. Israel é um dos países que mais investe em biotecnologia e em fontes de energia alternativas. E as experiências em torno dos Kibutz foi durante muito tempo fonte de esperança coletivista para qualquer socialista do mundo.

A "mudança de lado" da esquerda em boa medida ocorreu em paralelo aos fracassos do processo de paz e da tese da formação dos dois estados. Muravchik (2014) também argumenta que o lado palestino soube seduzir e falar a linguagem da Nova Esquerda principalmente ao inserir a luta dos palestinos por um estado num contexto mais amplo de luta anti-imperialista e pós-colonial.

A necessidade de "defender um lado" cria distorções perigosas. Grupos que monitoram a internet, como, por exemplo, o The Southern Poverty Law Center ${ }^{3}$ (SPLC) apontam para um outro fenômeno, a aliança entre militantes pró-islã com movimentos neonazistas e neofascistas. Há notícias de encontro de negacionistas do Holocausto em Teerã ${ }^{4}$ assim como palestra sobre mística sufi em eventos neofascistas em São Paulo 5 . No mais, numa simples busca, que qualquer pessoa possa fazer na internet, facilmente caímos em sites que se propõem ao mesmo tempo "apresentar o islã" e "falar a verdade" sobre Israel com extenso material antissemita. 0 que poderia explicar essas brechas e

\footnotetext{
2 Em rankings internacionais está melhor que o Brasil. Na Freedom House, Israel pontua 31 enquanto o Brasil 44. A pontuação ocorre numa escala de 0 a 100 na qual quanto mais perto de 0 mais livre é a mídia nacional.

${ }^{3}$ Grupo sediado nos EUA. Cf em < http://www.splcenter.org/> Acessado em 19/12/2014.

4 Cf. noticia em < http://seattletimes.com/html/nationworld/2003473161_iranholocaust12.html> Acessado em 18.12.2014.

${ }^{5}$ Cf. sobre o evento em < http://encontronacionalevoliano.com.br/> Acessado em 18.12.2014.
} 
alianças ideológicas? Talvez a simples lógica de que "o inimigo de meu inimigo é meu amigo" funciona agora para a esquerda como já funcionou em outros momentos também a para a direita. Lamentavelmente a esquerda pouco se manifesta sobre isso talvez temendo perder o foco de suas críticas ou por considerarem "eventos e manifestações isoladas".

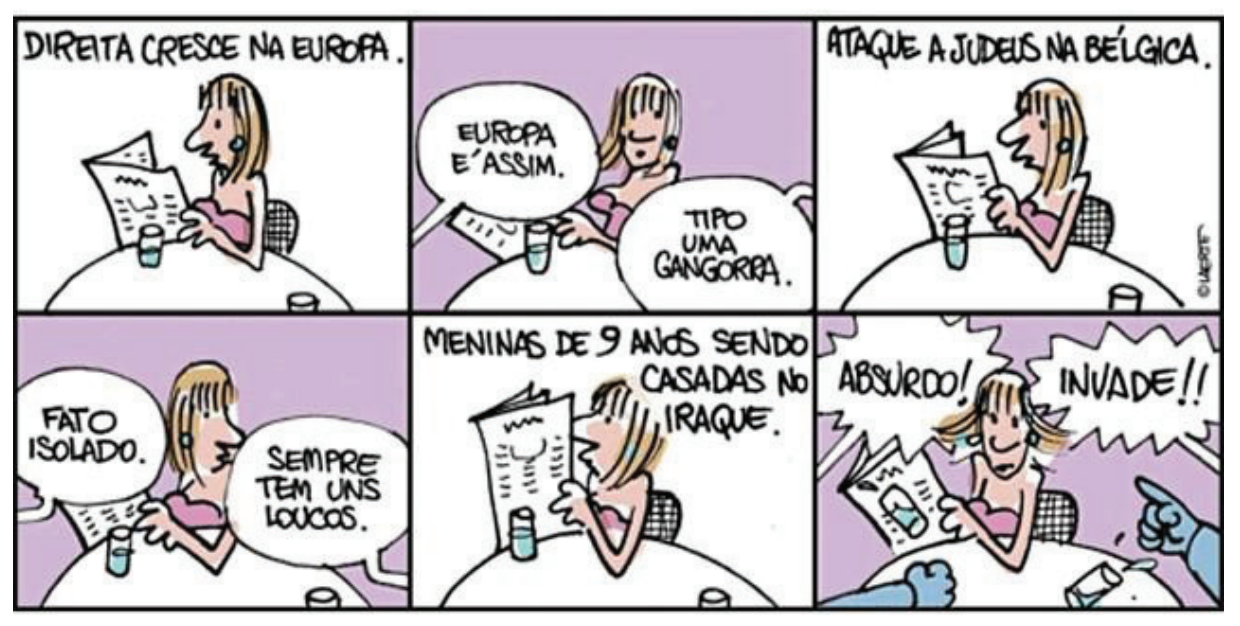

6

Por que a esquerda passou a lutar pela causa dos palestinos? Primeiramente porque se convenceram da existência de "palestinos" no sentido de ser uma identidade nacional em busca de uma autodeterminação e, segundo, porque também se convenceram que Israel havia se transformado em "estado terrorista", "fora da lei" quando não simplesmente um estado opressor, imperialista. Contudo é um mito achar que Israel é um estado "fora da lei", o que mudou foi que David virou Golias na metáfora de Joshua Muravchik.

Até 1967 não se falava em Estado Palestino. Durante a Guerra dos Seis Dias, muitos intelectuais de esquerda como Jean Paul Sartre ou mesmo Hannah Arendt se mobilizavam em seus respectivos países pedindo apoio internacional a Israel. E como

${ }^{6}$ Cartoon de autoria de Laerte Coutinho com copyright gentilmente autorizado para ilustrar esse texto. 
aponta Miscamble (19947) ao estudar as memórias, diários e correspondência de George F. Kennan sua recomendação era para que os EUA tivessem ressalva quanto ao apoio a Israel. É uma ilusão achar que os EUA são mais sionistas que os sionistas como as vezes acusa a esquerda.

Nos anos de 1970 o impacto da obra de Edward Said foi também decisivo para a causa palestina e para o convencimento das esquerdas. A tese do Orientalismo em forte ressonância com as teses de Michel Foucault de biopoder e em menor medida de habitus de Pierre Bourdieu colocavam o dedo na ferida, acusando o Ocidente de etnocentrismo e tornava gradativamente mais difícil - uma vez que nenhum pesquisador se sentiria à vontade com o rótulo de orientalista - criticar grupos até então simplesmente fundamentalistas como o Hizbollah ou o Hamas que aos olhos da esquerda ganharam status de "movimentos sociais" ou de movimentos de resistência.

Paira é verdade entre conservadores a ideia de que os vizinhos árabes de Israel sempre foram antissemitas. Muitos lembram do encontro de Haj Amin al-Husseini, então o líder islâmico do protetorado britânico na Palestina com Adolf Hitler em 1941. Outros lembram de inúmeras tentativas de países vizinhos de Israel que tentaram tornar inviável a formação do estado sionista. Outros argumentam que a Organização para a Libertação da Palestina (OLP) liderada por Yasser Arafat soube colocar a causa palestina entre os movimentos de luta e resistência da Guerra Fria apenas como uma escolha de estratégia política. Se o Vietnã serviu para reinventar a esquerda nos EUA, Arafat soube vincular os palestinos aos vietcongues e de repende Israel e os EUA se tornaram dois lados do mesmo império e enfrentaram esses poderes imperiais que passaram a unir a esquerda e a boa parte da opinião pública internacional.

Para muitos conservadores o antissemitismo árabe nunca deixou de existir e de tempos em tempos se revela. Grupos de Observação da Mídia Árabe como o Middle East Media Research Institute ${ }^{8}$ (MEMRI), com sede nos EUA, divulga boletins diários destacando declarações, debates, charges, cartoons, comentários da mídia em árabe que pregam a destruição de Israel ou que remetem a velhas teses antissemitas. Em certa medida, o trabalho do MEMRI tenta desconstruir o argumento que "toda culpa é do Ocidente" que os ocidentais são preconceituosos e imperialistas, tese que reverbera bem em certos setores da esquerda. Para muitos conservadores são os árabes e o Oriente

7 Cf. George F. Kennan and the Making of American Foreign Policy, 1947-1950. Ed. Princeton Press, NYC. 1994.

${ }^{8}$ Grupo com sede nos EUA. Cf em < http://www.memri.org/ > Acessado em 19/12/2014. 
Médio que propagam seu "Ocidentalismo". Dessa forma a mídia e a opinião pública internacional tornam-se um campo de batalha ideológica entre duas visões de mundo de muitas vezes funciona como uma "patrulha ideológica" que pouco de fato tem a debater e muitas vezes parte para o ataque a buscar culpados ou possíveis "orientalistas" ou "terroristas" a censurar. Parece uma contradição, mas a censura de tempos em tempos aprece no debate entre direita e esquerda frente ao Islã. Flemming Rose (2014 ${ }^{9}$ ) então editor do jornal dinamarquês Jyllands-Posten - que publicou uma seria de cartoons em torno do islã e seu profeta despertando uma grande reação internacional - chega a conclusão, com pesar, de que muitas vezes é a esquerda que sugere tentar controlar o debate ou que sugere a autocensura ${ }^{10}$. Com o debate polarizado, as sensibilidades se afloram e a racionalidade muitas vezes se perde. Qualquer imagem ou palavra descontextualizada alimenta uma Guerra Cultura, que divide as partes e cria distorções perigosas. Cada lado só consegue conversar com aqueles que já estão devidamente afinados ideologicamente. Estamos tão cegos e travados no debate público, que a frase de Thomas Jeferson do final do século XVIII parece o retrato do que temos no limiar do século XXI: "The man who reads nothing at all is better educated than the man who reads nothing but newspapers"11.

A situação no Brasil, por exemplo, chegou a um ponto que sionistas liberais são taxados de conservadores. Conservadores de fato são considerados extremistas, racistas etc. Muitos nomes de esquerda já foram - ou ao menos não veem conflito entre ser sionista e ser por exemplo -socialista ou simplesmente se sentem mais de esquerda do que de direita. Ser sionista não é sinônimo de ser de direita ou de esquerda. Amos $\mathrm{Oz}$ $\left(1983^{12}\right.$, p. 133) bem apresenta o argumento ao dizer que:

\footnotetext{
I have stated many times that Zionism is not a first name but a surname, a family name, and this family is divided, feuding over the question of a "master plan" for the enterprise: How shall we live here? Shall we aspire to build the kingdom of David and Solomon? Shall we construct a Marxist paradise here? A Western society, a social democratic welfare state? Or shall we create a model of the petit bourgeoisie diluted with a little yiddishkeit?
}

\footnotetext{
${ }^{9}$ Cf. The Tyranny of Silence: How One Cartoon Ignited a Global Debate on the Future of Free Speech. Ed. Cato Institute, Washington D.C. 2014.

10 Dois dias após a finalização desse texto terroristas invadiram a redação do jornal Charlie Hebdo - um jornal satírico de longa tradição provocadora com vários casos de publicações de cartoons críticos ou considerados ofensivos ao islã - matando 12 pessoas deixando outras tantas feridas.

11 In: Meet Thomas Jerfesson Cf. < http://thejeffersonians.com/Meet\%20Jefferson.html > Acessado em $19 / 12 / 2014$.

12 In the Land of Israel Ed. Fontana, Londres , 1983.
} 
A diferença entre um sionista liberal e o sionista conservador perpassa fundamentalmente pelo tema da solução dos dois estados para o conflito. Os sionistas liberais acreditam na solução de dois estados e lamentam a militarização do conflito. Os sionistas conservadores podem já ter acreditado na solução de dois estados, mas hoje não veem outra alternativa a não ser um grande Israel - como um estado judaico soberano - mantida a um alto preço militar. Em outras palavras, os sionistas liberais acreditam que ainda é possível lidar com o "problema palestino", já os conservadores apostam na contenção pura e simples. Na medida em que a solução de dois estados se revela mais improvável os sionistas liberais se veem num dilema existencial. Se Israel avançar para um estado sob toda Palestina diferenciando sua população judaica da palestina, ainda pode ser um projeto sionista, mas certamente não será mais liberal. E por outro lado, uma divisão rígida de territórios e de poderes criando dois estados nacionalistas em constante ameaça existencial, imaginemos uma Israel governada por um nacionalista e os palestinos por fundamentalistas certamente seria o fim tanto do sonho sionista como de qualquer aspiração liberal. Qual o futuro dos sionistas liberais? Talvez essa pergunta nos ajude a pensar também qual futuro terá a relação entre a esquerda e Israel. Cedo ou tarde, eles terão que escolher entre o sionismo sem liberalismo ou abrir mão de ambos? Esse dilema ecoa com força no debate doméstico israelense que tende a ver com reticência tanto declarações de apoio como de críticas que chegam da Opinião Pública Internacional.
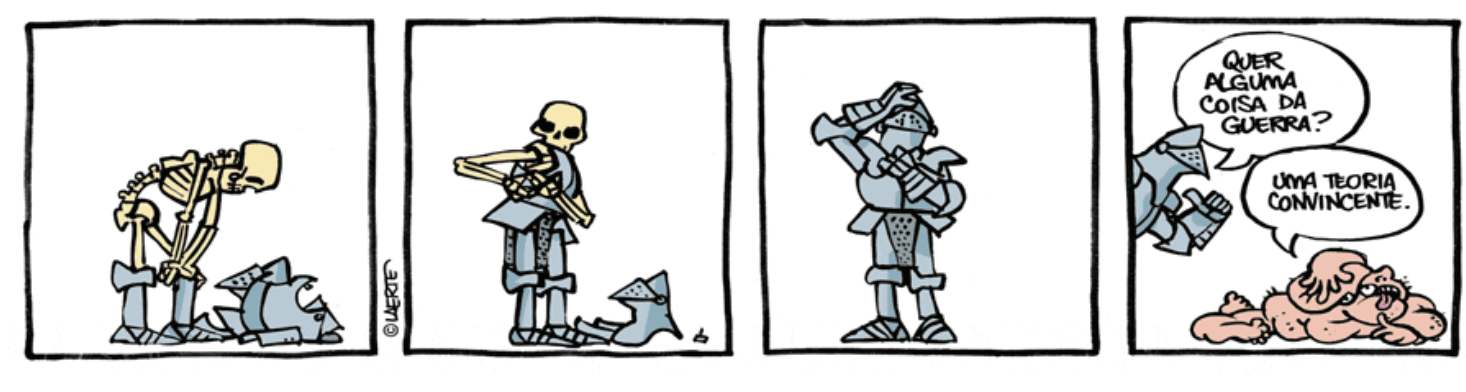

13

O que poderia destravar o debate? Talvez um pouco mais de ceticismo e menos paixão militante ajudaria. 0 ceticismo científico anda em baixa não só nas ciências 13 Obra de Laerte Coutinho com copyright, gentilmente autorizada a reprodução nesse texto meramente
em caráter ilustrativo. 
sociais e humanas, mas também já afeta o debate das ciências naturais e biológicas, o debate sobre mudanças climáticas e matriz energética é um triste exemplo.

Outro aspecto decisivo seria enfatizar e retomar o que o pai da sociologia chama de "olhar sociológico". O que quero dizer é que devemos deixar de buscar um Übermensch nietzschiano, aquela ideia de que a qualquer momento surgira um "novo" homem, um novo Nelson Mandela, um Martin Luther King ou mesmo um novo Che Guevara que irá liderar uma verdadeira revolução pondo fim ao conflito e inaugurando a tão esperada paz e o fim de todas as injustiças no conflito entre Israel e os Palestinos e nos voltarmos novamente aos fatos sociais. Em outras palavras é preciso mais serendipidade e menos materialismo histórico. È preciso estudarmos e olharmos como analistas para o conflito Israel - Palestino deixando nossas certezas e preconceitos de lado e procurar por respostas sem saber exatamente o que iremos encontrar. Creio que foi Antonio Gramsci que dizia algo sobre unirmos o pessimismo da razão com o otimismo da vontade.

Por fim, creio importante a ideia trazida por Stephen J. Dubner ${ }^{14}$, um dos coautores da séria Freakonomics, ele discute a economia digital, mas parece poder falar também para as dificuldades de pesquisa no conflito I-P e sobre Oriente Médio e Islã. Ele propõe que deixemos um pouco de lado a busca pela solução dos "grandes problemas" e passamos a olhar com mais atenção para o que de fato está acontecendo para o movimento e para como as coisas mudam. Em termos mais práticos creio que seja hora de deixarmos um pouco de lado a busca pela solução dos grandes temas/problemas do debate Israel-Palestina para debatermos e pesquisarmos com afinco as "pequenas coisas", olharmos para o que de fato está acontecendo e, assim, quem sabe, termos novas perspectivas, novas ideias, novo fôlego, uma nova possibilidade de debate para os grandes problemas/temas.

${ }^{14}$ Cf. podcast em < https://www.youtube.com/watch?v=fypkPgeQxBQ > Acessado em 23/10/2014. 